\title{
Effects of different Zinc levels in the sperm culture medium on sperm recovery and quality of sperms in the swim up procedure for sperm processing
}

${ }^{*}$ D. M. A. B. Dissanayake', P. S. Wijesinghe', W. D. Ratnasooriya ${ }^{2}$, S. Wimalasena ${ }^{3}$, T. S. Palihawadana ${ }^{1}$

The Ceylon Journal of Medical Science 2006; 49: 21-27

\begin{abstract}
A controlled in vitro study was carried out to observe the effect of different Zinc ( $\mathrm{Zn}$ ) levels on sperm recovery rate, chromosome integrity, cell membrane integrity and motility in the swim up procedure. Semen samples were obtained from males who underwent seminal fluid analysis at the Infertility Laboratory, Department of Obstetrics and Gynaecology, Faculty of Medicine, Ragama. Twenty normozoospermic samples were randomly selected for the study and each sample was processed with supplemented Earl's Balanced Salt Solution (EBSS) containing different concentrations of $\mathrm{Zn}[0.5 \mathrm{ml}$ of supplemented EBSS with $25 \mu \mathrm{l}$ of solution containing $0.6 \mu \mathrm{mol}$ (group 1) and $1.2 \mu \mathrm{mol}$ (group 2) of $Z$ n respectively]. One aliquot processed with $25 \mu \mathrm{l}$ of physiological saline with added EBSS served as the control. Pre and post wash sperm counts and motility were recorded immediately after processing. Post wash sperms from the three groups were observed for chromosome integrity, cell membrane integrity, and motility. Motility changes after four hours of incubation were also observed.
\end{abstract}

The mean sperm concentration showed an increase in group 1 compared to the control sample $[21.87 \pm 21.61(\mathrm{SD})$ millions $/ \mathrm{ml}$ compared to $18.34 \pm 19.73$ millions $/ \mathrm{ml}$, $\mathrm{P}<0.05$ ] whereas a reduction was observed in group 2 [16.25 $\pm 17.73(\mathrm{SD})$ millions $/ \mathrm{ml}$ compared to $18.34 \pm 19.73$ millions $/ \mathrm{ml}$, $\mathrm{P}>0.05]$. The mean differences in sperm concentration compared to the control showed statistically significant differences in both groups where an increase was observed in group 1 [3.52 \pm 4.96 (SD) millions $/ \mathrm{ml}$ ] and a reduction in group 2 $(-2.08 \pm 6.59$ millions $/ \mathrm{ml})$.

The mean differences in sperm recovery rate showed significant differences in group 1 $[8.97 \pm 14.04(\mathrm{SD})$ millions $/ \mathrm{ml}]$ and group 2 $(-4.85 \pm 17.92$ millions $/ \mathrm{ml})$ compared to the control. It was an increase in group 1 and a reduction in the sperm recovery rate in group 2.

A significant reduction in mean sperm motility was observed in group $2[67.33 \% \pm$ 18.52 (SD) vs. $91.00 \% \pm 9.60, \mathrm{P}<0.05]$ after four hours of incubation. Though a reduction was observed in group 1 it was not statistically significant $(83.33 \% \pm 8.72$ vs. $93.60 \% \pm 5.01, \mathrm{P}>0.05)$. The motility reduction was significantly greater in group 2 compared to group $1(26.01 \% \pm 20.24$ vs. $10.97 \% \pm 8.35, \mathrm{P}<0.05)$. Chromosome integrity and cell membrane integrity of sperms were not affected by different $\mathrm{Zn}$ levels.

1. Department of Obstetrics and Gynaecology, Faculty of Medicine, University of Kelaniya, Sri Lanka.

2. Department of Zoology, Faculty of Science, University of Colombo, Sri Lanka.

3. Department of Chemistry, Faculty of Science, University of Kelaniya, Sri Lanka.

* Corresponding author. Received on July 7, 2006 and revised version accepted on October 5, 2006. 
In conclusion, low levels of $\mathrm{Zn}$ in the sperm processing medium (EBSS) have a beneficial effect on sperm recovery in the swim up procedure.

Key Words: Zn added EBSS, Harvesting rate, Chromosome integrity, Cell membrane integrity, motility.

\section{Introduction}

Management of male factor subfertility involves assisted reproductive technologies (ART) (1). Obtaining a good yield of high quality spermatozoa is a vital step in these techniques. Commonly used sperm processing techniques include swim up, density gradients centrifugation, glass wool filtration, migration sedimentation and centri-swim procedure $(2,3,4)$. In practice they have their own advantages and shortcomings, and there is no clear evidence to suggest that one method is superior to another when pregnancy rates are considered $(4,5)$.

Whatever the technique used, culture media with minor differences in composition are used in washing the sperm. All culture media generally contain essential salts, energy substrates, a nitrogen source and a buffer. Several adjuvants including caffeine, pentoxifylline, follicular fluid, progesterone, platelet activating factor, cytokines, kallikrein, bicarbonate, metal chelators and some vitamins have been used to enhance sperm function and to minimize intercellular stress by providing a protective environment $(6,7,8,9)$. Some have also incorporated antioxidants to sperm culture media but their beneficial effect on sperm function is not clearly established. Whether antioxidants improve the sperm function and subsequent fertilization capacity is an important area for further research (10).
Zinc $(\mathrm{Zn})$ is present in high concentrations in seminal fluid and plays a multifaceted role in sperm functions (11). It helps to stabilize the cell membrane and nuclear chromatin of spermatozoa and is reported to be the primary factor responsible for antibacterial activity (12). Zn influences sperm motility and plays a regulatory role in the process of capacitation and acrosome reaction $(13,14)$. The antioxidant capacity of $\mathrm{Zn}$ has been reported by many authors (15). EBSS is one of the recommended media in the WHO manual for sperm processing (16). However, $\mathrm{Zn}$ is not a component of this medum, though other cations such as magnesium and calcium are included. The aim of the present study was to investigate whether the incorporation of $\mathrm{Zn}$ in the EBSS culture medium improves sperm recovery rate in the swim up procedure.

\section{Material and Methods}

The study was carried out as a laboratory based controlled study at the University Infertility Laboratory at Ragama. Ethical clearance was obtained from the Ethics Committee, Faculty of Medicine, Ragama.

Twenty males attending the infertility clinic with normozoospermia. [based on the selection criteria in WHO manual 1999 (16)] over a period of three months from January 2006 were included. Semen samples were collected into sterile containers (Bibby Sterilin Ltd., England) and analysed within 30 minutes of collection. Immediately after the analysis, each sample was processed according to the swim-up sperm preparation method using the supplemented EBSS with added $\mathrm{Zn}$.

Preparation of $\mathrm{Zn}$ solutions: $\mathrm{Zn}$ solutions of different concentrations were prepared using analytical reagent grade $\mathrm{ZnSO}_{4}(\mathrm{BDH}$, Poole, England) and normal saline $(0.9 \% \mathrm{w} / \mathrm{v})$; 
$13.8 \mathrm{mg}$ of $\mathrm{ZnSO}_{4} \cdot 7 \mathrm{H}_{2} \mathrm{O}$ was dissolved in 1 $\mathrm{ml}$ of physiological saline; $25 \mu \mathrm{l}$ of this solution contains $1.2 \mu \mathrm{mol}$ of $\mathrm{Zn}$.

Sperm processing: For a given seminal fluid sample three conical centrifuge tubes containing $0.5 \mathrm{ml}$ of human serum albumin added EBSS (Sigma Chemical Co., St. Louis, USA) were prepared. To one tube $25 \mu$ l of solution containing $0.6 \mu \mathrm{mol}$ of $\mathrm{Zn}$ was added (group 1); $25 \mu \mathrm{l}$ of solution containing $1.2 \mu \mathrm{mol}$ of $\mathrm{Zn}$ was added to another tube (group 2). A third tube with $25 \mu \mathrm{l}$ of physiological saline solution without $\mathrm{Zn}$ served as the control. Each tube was gently under layered with $0.5 \mathrm{ml}$ of a well mixed semen sample. Tubes were inclined at an angle of $45^{\circ}$ and placed in an incubator (Sanyo MCO-17AIC-U, Loughborough, England) for one hour at $37^{\circ} \mathrm{C}$ in $5 \% \mathrm{CO}_{2}$ environment. Subsequently the uppermost $0.4 \mathrm{ml}$ was diluted with $2.8 \mathrm{ml}$ of EBSS medium and centrifuged (Fisher Scientific Model 225, Litho, U.S.A.) at $500 \mathrm{~g}$ for 5 minutes. The sperm pellet formed was resuspended in $0.5 \mathrm{mI}$ of EBSS. The resuspended sperms were assessed for motility, chromosome integrity and cell membrane integrity. Samples were incubated at $37^{\circ} \mathrm{C}$ in $5 \% \mathrm{CO}_{2}$ for further four hours and reassessed for motility. Groups 1 and 2 were compared against the control group with regard to the above parameters. Percentage of sperm harvested from the raw sample (recovery rate) was calculated using the following equation.

Percentage of sperm harvested from the raw sample $=($ Total motile sperm population in washed sample / Total motile sperm population in raw semen sample) $\times 100$.

Assessment of motility and count: Sperm motility and count were assessed using a Makler counting chamber (Sefi Medical, Israel). Samples were observed under a phase contrast microscope (Magnus Mxt, New Delhi, India) at a magnification of 400. Evaluation of chromosome integrity: The method followed was originally described by Tajeda et. al. in 1984 (17). Sperm smears were prepared on clean glass slides and air dried. They were fixed in Carnoy's solution ( 3 part methanol and 1 part glacial acetic acid) overnight at room temperature. Slides were removed from the fixer and air dried for three minutes, stained with acridine orange $(\mathrm{AO})(\mathrm{BDH}$, Poole, England) for five minutes. The slides were then gently rinsed with deionized water and mounted with cover glass before drying. They were read under a fluorescence microscope (Olympus $\mathrm{CH} 40$, Tokyo, Japan) using 490nm excitation and $530 \mathrm{~nm}$ barrier filters $(x 40)$. At least 200 spermatozoa were counted. Green heads were counted as normal and yellow to red sperm heads as abnormal.

Assessing cell membrane integrity by the hypo-osmotic swelling test (HOS Test): Washed sperm samples $(0.1 \mathrm{ml})$ were mixed with $1 \mathrm{ml}$ swelling solution $(0.735$ sodium citrate dihydrate and $1.351 \mathrm{~g}$ fructose in 100 $\mathrm{ml}$ of distilled water) and incubated at $37^{\circ} \mathrm{C}$ for 30 minutes. A drop of the mixture was placed on a clean glass slide and covered with a cover glass $(22 \mathrm{~mm} \times 22 \mathrm{~mm})$. The number of swollen sperms (sperms with curved or bent tails) in each slide was counted using a phase contrast microscope at a magnification of 400 .

\section{Statistical Analysis}

Analysis was done using SPSS 10.0 for windows. The results are presented as mean \pm standard deviation (SD) except sample population means which are expressed as mean \pm standard error of the mean (SEM). Comparison between means of $\mathrm{Zn}$ treated groups and controls was done using the Student's t-test and ANOVA. 


\section{Results}

The sample population had a mean seminal fluid volume of $3.04 \pm 0.26 \mathrm{ml}$, a mean concentration of $68.30 \pm 6.9$ millions $/ \mathrm{ml}$ and a mean sperm motility of $61.60 \pm 3.8 \%$.

The mean post wash sperm concentration, percentage of motile sperms in the processed samples and the sperm recovery rates are shown in Table 1 . The mean \pm SD sperm concentration showed an increase in the group 1 compared to the control sample (21.87 \pm 21.61 millions $/ \mathrm{ml}$ compared to $18.34 \pm 19.73$ millions $/ \mathrm{ml}, \mathrm{P}<0.05)$ whereas a reduction was observed in group 2 (16.25 \pm 17.73 millions $/ \mathrm{ml}$ compared to $18.34 \pm$ 19.73 millions $/ \mathrm{ml}, \mathrm{P}>0.05)$. The mean differences in sperm concentration compared to the control showed statistically significant differences in both groups where an increase was observed in group 1 (3.52 \pm 4.96 millions $/ \mathrm{ml}$ ) and a reduction in group $2(-2.08 \pm 6.59$ millions $/ \mathrm{ml})$.

The mean percentage motility was not different between the control, group 1 and group $2(91.80 \% \pm 7.50 ; 93.60 \% \pm 5.01$; $91.00 \% \pm 9.60, \mathrm{P}>0.05)$.

The mean differences in sperm recovery rate showed significant differences in group 1 $(8.97 \% \pm 14.04)$ and group $2(-4.85 \% \pm 17.92)$ compared to the control. It was an increase in group 1 and a reduction in the sperm recovery rate in group 2 .

Changes in mean sperm motility were assessed following incubation of the processed sperm sample in $\mathrm{Zn}$ added media. The group 1 and 2 results are shown in Table 2. A significant reduction in mean sperm motility was observed in group $2(67.33 \% \pm$ 18.52 vs. $91.00 \% \pm 9.60, \mathrm{P}<0.05)$. Though a reduction was observed in group 1 it was not statistically significant $(83.33 \% \pm 8.72$ vs. $93.60 \% \pm 5.01, \mathrm{P}>0.05)$.

The motility reduction was significantly greater in group 2 compared to group 1 $(26.01 \% \pm 20.24$ vs. $10.97 \% \pm 8.35, \mathrm{P}<0.05)$.

The chromosomal integrity was not affected significantly by the addition of either concentration of $\mathrm{Zn}$ as evident by an absence of any difference in the number of sperms with red heads in either sample at the $\mathrm{AO}$ test. A similar observation was made with regard to cell membrane integrity as evident by the percentage of curve tailed sperms (Table 3).

Table 1. Comparison of sperm recovery rate, post wash count and motility with different $\mathrm{Zn}$ levels (mean $\pm \mathrm{SD}),(\mathrm{n}=20)$

\begin{tabular}{lcccc}
\hline Parameter & Pre wash & \multicolumn{3}{c}{ Post wash } \\
\hline & & Control & Group 1 & Group 2 \\
\hline $\begin{array}{l}\text { Volume (ml) } \\
\text { Concentration } \\
\text { (millions } / \mathrm{ml})\end{array}$ & $3.04 \pm 1.01$ & 0.5 & 0.5 & 0.5 \\
$\begin{array}{l}\text { Sperm recovery rate (\%) } \\
\text { Motility (\%) }\end{array}$ & $68.30 \pm 26.75$ & $18.34 \pm 19.73$ & $21.87 \pm 21.61^{*}$ & $16.25 \pm 17.73$ \\
& & $61.87+37.64$ & $72.82+27.01^{*}$ & $52.64 \pm 38.33$ \\
& $61.60 \pm 10.02$ & $91.80 \pm 7.50$ & $93.60 \pm 5.01$ & $91.00 \pm 9.60$ \\
\hline
\end{tabular}

${ }^{*} \mathrm{p}<0.05$, compared to control

$\mathrm{SD}=$ Standard deviation 
Table 2. Change in sperm motility following incubation in media containing different levels of $\mathrm{Zn}$. (mean $\pm \mathrm{SD}),(\mathrm{n}=20)$

\begin{tabular}{lccc}
\hline & Control & Group 1 & Group 2 \\
\hline Motility \% $(0 \mathrm{hr})$ & $91.80 \pm 7.50$ & $93.60 \pm 5.01$ & $91.00 \pm 9.60$ \\
Motility $\%(4 \mathrm{hr})$ & $78.83 \pm 14.31$ & $83.33 \pm 8.72$ & $67.33 \pm 18.52$ \\
$\%$ motility reduction & $14.13 \pm 10.24$ & $10.97 \pm 8.35$ & $26.01 \pm 20.24^{*}$ \\
\hline
\end{tabular}

${ }^{*} \mathrm{p}<0.05$, compared to 0 hour

$\mathrm{SD}=$ Standard deviation

Table 3. Results of Acridine Orange (AO) and Hypo-osmotic swelling test (HOS Test) in the three groups (mean $\pm S D),(n=20)$

\begin{tabular}{lccc}
\hline & Control & Group 1 & Group 2 \\
\hline AO test (green cells \%) & $92.38 \pm 9.25$ & $94.92 \pm 6.29$ & $88.46 \pm 16.42$ \\
HOS test (swollen sperms \%) & $81.83 \pm 13.92$ & $80.00 \pm 10.50$ & $84.14 \pm 9.13$ \\
\hline
\end{tabular}

$\mathrm{SD}=$ Standard deviation

\section{Discussion}

The WHO reference level of $\mathrm{Zn}$ in human semen ejaculate is $2.4 \mu \mathrm{mol}$ or more per total ejaculate (16).

The major contributor of $\mathrm{Zn}$ in the ejaculate is the prostate gland which plays a minor role in determining the total seminal fluid volume. The seminal fluid volume is mainly made of secretions from the seminal vesicles.

In this study the three groups make three seminal fluid environments with different concentrations of $\mathrm{Zn}$. The control samples did not have any $\mathrm{Zn}$ while group $1 \mathrm{had} \mathrm{a} \mathrm{Zn}$ concentration of $1.2 \mu \mathrm{mol} / \mathrm{ml}$. This is the same as the physiological $\mathrm{Zn}$ concentration of $1.2 \mu \mathrm{mol} / \mathrm{ml}$. Group 2 contained a higher concentration of $\mathrm{Zn}$.

The sperm recovery rate was optimal in group 1 whereas in the control (without $\mathrm{Zn}$ ) and in group 2 this was significantly reduced. The reduction in the sperm recovery rate as the $\mathrm{Zn}$ concentrations deviate from the physiological levels is a novel finding which may have a clinical significance.

Reason for this increase in harvesting rate with addition of $\mathrm{Zn}$ could be attributed to increased antioxidant capacity of $\mathrm{Zn}$. Antioxidants are reported to protect sperm membrane lipid from peroxidation and stabilize the membrane (13). As most of sperm functions are membrane functions $\mathrm{Zn}$ may help to improve their functional capacity by creating a favourable environment.

Progressive motility of sperms may be regulated by some divalent cations $\left(\mathrm{Ca}^{++}\right.$, $\mathrm{Mg}^{++}$and $\left.\mathrm{Zn}^{++}\right)$. However, the inhibitory or stimulatory effect on motility by these 
cations depends on the concentration of each cation (14). It is well known that $\mathrm{Zn}$ interacts with other cations simultaneously in some functions of spermatozoa eg. $\mathrm{Zn} / \mathrm{Cadmium}$ ratio affects the sperm motility and levels of antisperm antibodies (18). Some metalloenzymes such as lactate dehydrogenase and sorbitol dehydrogenase are known to contain $\mathrm{Zn}$ and they may help to the increase in sperm motility (19).

Favourable environment created by balanced ionic composition and increase in sperm motility through some mechanisms are other possible explanations for increase in harvesting rate in group 1.

Excess free $\mathrm{Zn}$ ion concentration in the media may act as a mechanical barrier to swim up is the reasonable explanation for reduction of the harvesting rate seen with high $\mathrm{Zn}$ levels in group 2. Addition of high levels of $\mathrm{Zn}$ to EBSS media caused a significant reduction in the percentage of motile sperms following four hours of incubation. The motility reduction could be due to elevated free $\mathrm{Zn}$ fraction and subsequent uptake by spermatozoa (20) and reduction of oxygen consumption, since high levels of $\mathrm{Zn}$ in semen impairs the oxygen consumption of sperms (21).

The chromosome integrated or green cells percentage was $>70 \%$ in all samples and means were not significantly different between the $\mathrm{Zn}$ treated groups and the control. Similarly in Hypo-osmotic swelling test (HOS Test), the number of swollen sperms did not significantly differ at different $\mathrm{Zn}$ levels. AO test and HOS Test confirmed that semen preparation procedure (subjected to centrifugation force and elimination of most of $\mathrm{Zn}$ from the spermatozoa) and addition of extra $\mathrm{Zn}$ to the culture media does not alter the chromosome integrity and functional integrity of plasma membrane of sperm cells.
In conclusion, this study suggests that incorporation of $\mathrm{Zn}$ into the EBSS in concentrations close to the physiological range is beneficial in harvesting motile sperms in swim up procedure. But the optimum level favourable for sperms should be determined by testing different concentrations taking the sperm functional status also into consideration.

\section{Acknowledgements}

Authors wish to thank the National Science Foundation (NSF) for the financial assistance under the research grant number RG/2004 / $\mathrm{M} / 14$.

\section{References}

1. Berkovtz A., Eltes F., Soffer Y., Zabludovsky N., Beyth Y., Farhi J., Levran D., Bartoove B. ART success and in vivo sperm cell selection depend on the ultra morphological status of spermatozoa. Andrologia. 1999; 31: 357-361.

2. Hammadeh H.E., Kuhnen A., Amer A.S., Rosenbauna P., Schmdt W. Comparison sperm preparation methods: effect on chromatin and morphology recovery rates and their consequences on the clinical outcome after in vitro fertilization embryo transfer. International Journal of Andrology. 2001; 24: 360-364.

3. Biefeld P., Babbo J., Ozornek H.M., Krussel J.S., Schuppe H.C., Hecht B.R., Jayendran R.S. A new Centri Swim procedure to increase the recovery of motile spermatozoa. Andrologia. 2001; 33: 356-358.

4. Babbo C.J., Hecht B.R., Jayendran R.S. Increased recovery of swim-up spermatozoa by application of "antigravitational" centrifugation. Fertility and Sterility. 1999; 72: 556-558. 
5. Morales P., Vantman D., Barros C., Vigil $P$. Human spermatozoa selected by percoll gradient or swim-up are equally capable of binding to human zona pellucida and undergoing the acrosome reaction. Human Reproduction. 1991; 6: 401-404.

6. Brijinder S., Minhas B.A., Ripps B.S. Methods for enhancement of sperm function. Frontiers in Bioscience. 1996; 1: 65-71.

7. Morales P., Lianos M., Yovich J.L., Cummin J.M., Vigil P. Pentoxyfylline increases sperm penetration in to zona free hamster oocytes without increasing the acrosome reaction. Andrologia. 1993; 25: 359-362.

8. Krausz C., Gervasi G., Forti G., Baldj E. Effect of platelet activating factor on motility and acrosome reaction on human spermatozoa. Human Reproduction. 1994; 9: 471-476.

9. Grigoriou O., Makrakis E., Konidaris S., Hassiacus D., Papadias K., Baka S., Creatsas G. Effect of sperm treatment with exogenous platelet activating factor on the outcome of intrauterine insemination. Fertility Sterility. 2005; 83: 618-621.

10. Ombelet W., Deblaere K., Bosmans E., Cox A., Jacobs P., Jonssen M., Nijs M. Semen quality and intrauterine insemination. Reproductive Biomedicine. 2003; 7: 485-492.

11. Kruse W.E., Zwick E.M., Batschulat K., Rohr G., Ambuster F.P., Petzoldt D., Strowitzki T. Are zinc levels in seminal plasma associated with seminal leucocytes and other determinants of semen quality. Fertility Sterility 2002; 77: 260-269.

12. Chia S.E., Ong C.N., Chua L.H., Ho L.M., Tay K.S. Comparison of Zinc concentrations in blood and seminal plasma and the various sperm parameters between fertile and infertile men. Journal of Andrology. 2000;21: 53-7.
13. Hidiroglou M., Knipfel J.E. Zinc in mammalian sperm: a review. Dairy Science. 1984; 67: 1147-1156.

14. Umeyama T., Ishikawa H., Takeshima H., Yoshii S., Koiso K. A comparative study of seminal trace elements in the fertile and infertile men. Fertility and Sterility. 1986; 46: 494-499.

15 Ykocg O.L., Ozdal M., Celik S., Balaban $\mathrm{N}$. Antioxident activity of seminal plasma in infertile and fertile men. Andrologia; 2003; 35: 233-237.

16. World Health Organization. Laboratory manual for the examination of human semen and sperm-cervical mucus interaction. Fourth edition. Cambridge; Cambridge University Press, 1999.

17. Tejada R.I., Mitchel J.C., Norman A., Marik J.J., Friedman S. A test for the practical evaluation of male fertility by acridine orange (AO) fluorescence. Fertility and Sterility. 1984; 42: 87-91.

18. Omu A.E., Fernandes $S$. The relationship between zinc/ cadmium ratio in human semen: Effect on immune response. The Kuwait Medical Journal 2001; 33: 38-43.

19. Elzanaty S., Richthoff J., Malm J., Giwercman A. The impact of epididymal and accessory sex gland function on sperm motility. Human Reproduction. 2002; 17: 2904-2911.

20. Carpino A., Siciliano L., Petrone M., Stefano C., Aquila S., Ando S. Low seminal Zinc bound to high molecular weight proteins in asthenozoospermic patients: evidence of increased sperm Zn content in oligoasthenozoospermic patients. Human Reproduction. 1998; 13: 111-114.

21. Wong W.Y., Flik G., Groenen P.M.W., Swinkels D.W., Thomas C.M.G., Copius-Peereboom J.H.J., Merkus H.M. W.M., Steegers-Theunissen R.P.M. The impact of calcium, magnesium, zinc and copper in blood and seminal plasma on semen parameters in men. Reproductive Toxicology. 2001; 15: 131-136. 